\title{
Curriculum Construction about Automotive Maintenance Major in Higher Vocational College Based on Task-guided and Action-oriented - Taking SGAVE as an Example
}

\author{
Hongliang $\operatorname{Lin}^{1,}$ a \\ ${ }^{1}$ Shaanxi College of Communication Technology, Wenjing Road 19 ${ }^{\text {th }}$, Xi'an City, Shaanxi Province, \\ 710018, China \\ alin_hong_liang@163.com
}

Keywords: High vocational education; Personnel training; SGAVE project; Task-guided; Action-oriented teaching

\begin{abstract}
With the continuous development of modern science and technology, as well as the global economic recession and the new normal of economic development in China, it is important to study how vocational education can make the young generation qualified to the job requirements and achieve the ideal employment so as to long-term development. Around the core of "professional ability training", according to the "learning field" curriculum model, training course about automotive mechanical and electrical technology was divided into 8 learning fields, 43 learning situations in SGAVE project. Based on customer oriented, practice oriented and ability oriented, integrated curriculum implementation plan was built according to action oriented teaching theory, which consisting of "client consignation" to introduce learning goal, "action oriented" teaching to achieve autonomous learning and "qualification matrix" evaluation of learning effectiveness. The curriculum mode realized the comprehensive vocational ability training and "spiral advanced" featured by "raising problems----analyzing problem----solving problem".
\end{abstract}

\section{Introduction}

Dual system of vocational education mode in German has a prominent role in realizing the employment of young people and supporting the "made in Germany", therefore becomes one of the most successful vocational education mode on the world. At the same time, Germany vocational education research has always leading the trend of the vocational education. The world's largest chemical company BASF education specialists believe: the active spirit of vocational education is not just to get a job, but to do vocational career plan and to train the next generation. In the curriculum research, German curriculum expert Birgit Berger believes that with human life and work more scientific, learners must be able to cope with the challenges of the modern knowledge products' constantly updating and grasping the interdisciplinary knowledge more quickly in order to cultivate comprehensive occupation ability of self. Therefore, in the dual background of modern science and technology rapid developing meanwhile the global economic downturn and new economic norm in China, it has important practical significance on how to make the young generation qualified and to realize the ideal employment so as to reach long-term development to vocational education.

Against this background, Sino-German automotive vocational education project (hereinafter referred to as the SGAVE project) was put forward by Ministry of education of PRC and German international cooperation agency (GIZ), along with five German automotive manufacturer jointly including Audi, BMW, Daimler, Porsche and Volkswagen in 2012. The SGAVE project is an international education cooperation project, which aiming to make full use of Germany strong technical experience in automotive field and advanced vocational education mode, so as to construct modern automotive maintenance industry and training system to meet the talent demand in China. From the current implementation of a nationwide 25 pilot higher vocational colleges, the students from SGAVE class have showed strong interesting in learning which leading to efficient learning and good evaluation from 
enterprises. SGAVE project has shown great vitality and vigor. Therefore it has important practical significance to study the characteristic and curriculum of SGAVE project.

\section{Action-oriented Curriculum Theory}

The construction of curriculum must revolve around the core of "professional competence", and training of professional ability must be closely attached to the actual work. German vocational education experts referred that vocational ability is the ability to learn and exhibit in the occupation, society and life which also would be self-responsible behavior ability. Vocational ability also can be reflected by the explicit behavior, that is, improvement of intelligence level, psychological quality of training and formation of good professional attitude can be reflected by the maturity degree of behavior. On the basis of such a comprehensive professional ability, German scholars have put forward the "learning field" curriculum model about vocational education. Professor Baader and Schafer's, German curriculum experts, had put forward the concepts of learning field, action field and study situation and built the feedback principle about those according to "teaching feedback" theory.

So, curriculum of SGAVE class should be built according to task-guided and action-oriented theory. Among them, analysis about working process is the premise and foundation of design learning field and learning situations, which also is the key to determine a customer commission, teaching goal and professional ability. The curriculum, which emphasizing on vocational education curriculum should follow the principle of professional relevance, would be built by working process as the logic clue of course and break traditional discipline system.

\section{Curriculum Construction of SGAVE Model}

Establishment of Customer's Commission. Customer's commission is the start of the whole operation process. So, we should select typical working task in service workshop as customer commission, meanwhile construct the learning situation simulating the actual work. A whole customer's commission, that is a learning process for students, is shown in Fig.1.

Curriculum Design. Considering students' actual work and personal development needs, three principals were put forward in curriculum construction of SGAVE project, which including customer oriented, practice oriented and ability oriented. In other words, curriculum should meet the cultivation of students' comprehensive professional ability. So, curriculum of SGAVE project was designed from actual working and customer demand view, which following curriculum design, learn and work three main lines. Firstly, customer's commission was introduced to build working scene meanwhile as a "starting point" in the action process. Then action oriented teaching was performed in training process in order to stimulate students' autonomous learning. Thirdly, qualification matrix was used to describe and evaluate the learning effect. The combination of curriculum design, learning process and work process was shown in Fig. 2.

According to above ideas, curriculum of SGAVE project was divided into eight learning fields, and each learning field was consist of a number of learning situations based on the relevance of actual working. Learning field refers to the field of vocational action and is embodied by the learning situation. In the process of learning situation construction, design of learning tasks should focus on two key points: one is that learning task should be ordered in accordance with whole-partial-whole so as to establish overall concept for students; the other is that learning task should follow "spiral upward" idea, that is task design should deepen from easy to difficult and term reproduction so as to meet the students' learning rules. Through improvement and optimization of curriculum, ability of solving complex problem for students would be trained to adapt to social development and change of work quality requirements. 


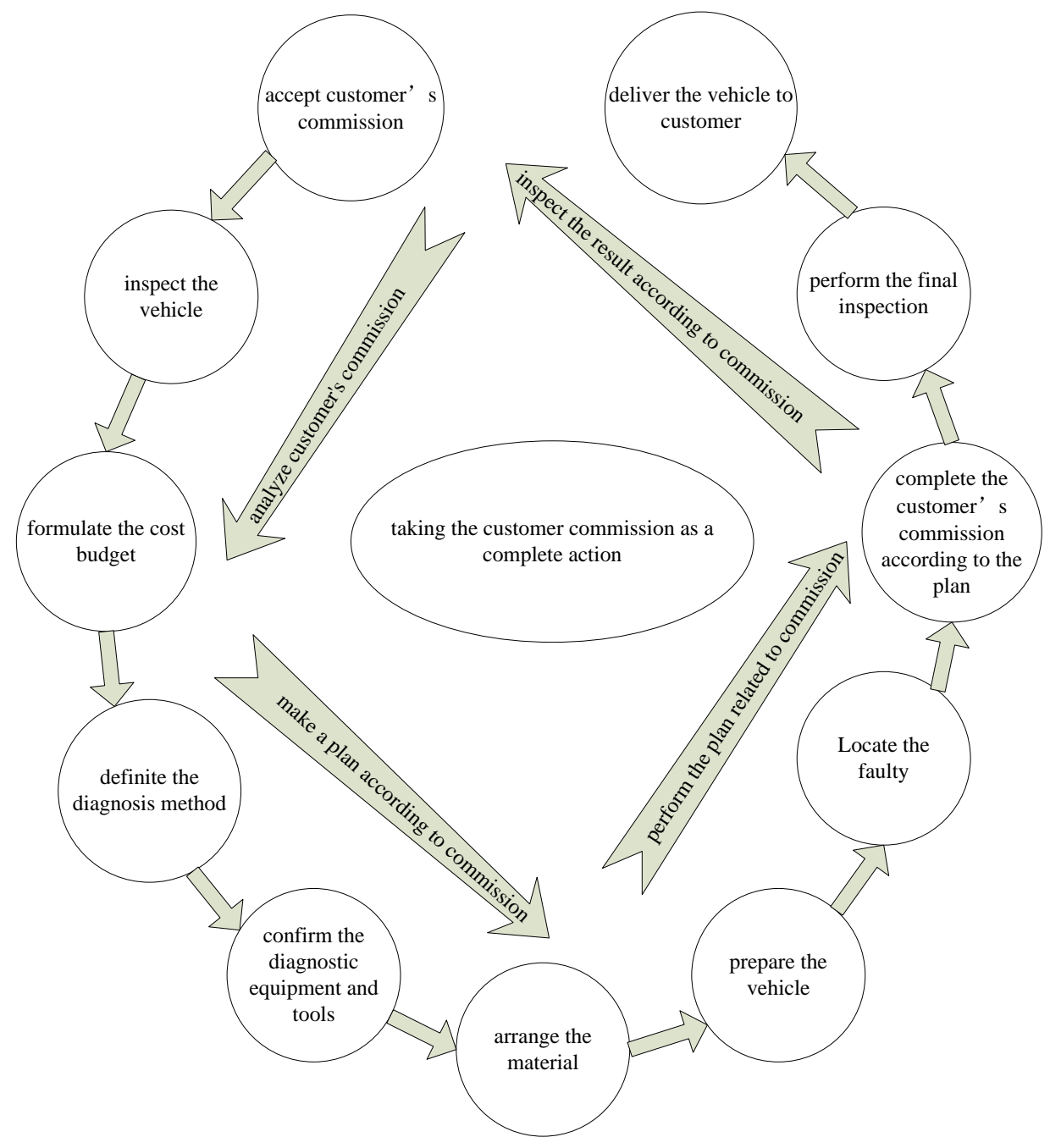

Figure 1. Deal with customer's commission: complete action

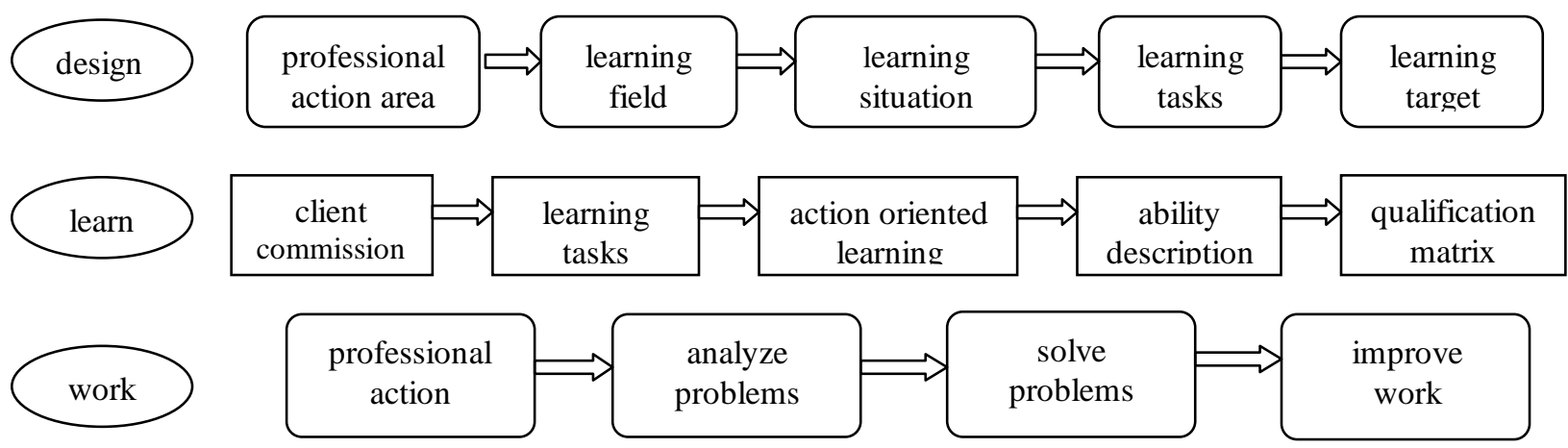

Figure 2. Curriculum structure design

Teaching Organization and Implementation. To a learning situation, teaching reference materials including working mission, learning task and ability description should be set up in the process of teaching. Working mission is reference to practice a customer commission which contains all requirements of client (customer) to trustee (automotive mechatronic engineer). Learning task refers that student should follow self-organization and application-guided principle in the process of learning and achieve the capabilities to perform the working mission; Ability description is used to describe the knowledge and skills of profession and method to perform tasks. The process of plan and complete customer's commission independently is shown in Fig. 3. 
Table 1 Learning field and learning situationg of SGAVE

\begin{tabular}{|c|c|c|}
\hline No. & Learning field & Learning situation \\
\hline 1 & automotive maintenance & $\begin{array}{l}\text { to prepare a new car and deliver to the } \\
\text { customer and other } 3 \text { situations }\end{array}$ \\
\hline 2 & $\begin{array}{l}\text { diagnosis and maintenance of engine } \\
\text { mechanical system }\end{array}$ & $\begin{array}{l}\text { to inspect,diagnose,remove, install and } \\
\text { repair basic engine and other } 3 \text { situations }\end{array}$ \\
\hline 3 & $\begin{array}{l}\text { Electrical systems and energy/starting } \\
\text { system diagnosis and maintenance }\end{array}$ & $\begin{array}{l}\text { to inspect, upgrade, diagnose and repair } \\
\text { electrical/electronic circuit and other } 11 \\
\text { situations }\end{array}$ \\
\hline 4 & $\begin{array}{c}\text { diagnosis and maintenance of engine } \\
\text { management system }\end{array}$ & $\begin{array}{l}\text { to inspect,diagnose and repair exhaust } \\
\text { system and other } 5 \text { situations }\end{array}$ \\
\hline 5 & $\begin{array}{c}\text { diagnosis and maintenance of powertain } \\
\text { system }\end{array}$ & $\begin{array}{l}\text { to inspect, diagnose and repair manual } \\
\text { transmission and other } 4 \text { situations }\end{array}$ \\
\hline 6 & $\begin{array}{l}\text { diagnosis and maintenance of travelling and } \\
\text { control system }\end{array}$ & $\begin{array}{c}\text { to inspect,diagnose and repair wheel and } \\
\text { tyre and other } 5 \text { situations }\end{array}$ \\
\hline 7 & $\begin{array}{l}\text { diagnosis and maintenance of alternative } \\
\text { fuel powertrain system }\end{array}$ & $\begin{array}{l}\text { to operate the high voltage equipment } \\
\text { complied with the safety regulations and } \\
\text { other } 2 \text { situations }\end{array}$ \\
\hline 8 & $\begin{array}{l}\text { communication and interaction in } \\
\text { automotive service station }\end{array}$ & $\begin{array}{l}\text { to communicate and interact with the } \\
\text { customer and other } 3 \text { situations }\end{array}$ \\
\hline
\end{tabular}

\section{Summary}

Compared with the traditional knowledge system for curriculum development, SGAVE project combined vocational education theory with professional action field closely together to construct curriculum system. Therefore, teaching process can reflect situation and requirements of actual work and life, meanwhile with the continuous working process of the teaching situation as reference to reproduce the whole actual working process in students ' minds.

Aiming at the goal of automotive mechatronic talents training, curriculum of SGAVE project, which combined "learning process" with "working process" together, was divided into 8 learning areas, 43 learning situations on the basis of customer-oriented, practice-oriented and ability -oriented principle. The integrated curriculum was built which characteristic by "customer commission" guiding learning task, "action oriented" teaching realization of autonomous learning and "qualification matrix" evaluating the learning effect. Through the implementation of this curriculum plan, cultivate comprehensive professional ability of students including raise problems- analyze problems-solve problems was trained and realized students' ability of "spiral upward". 


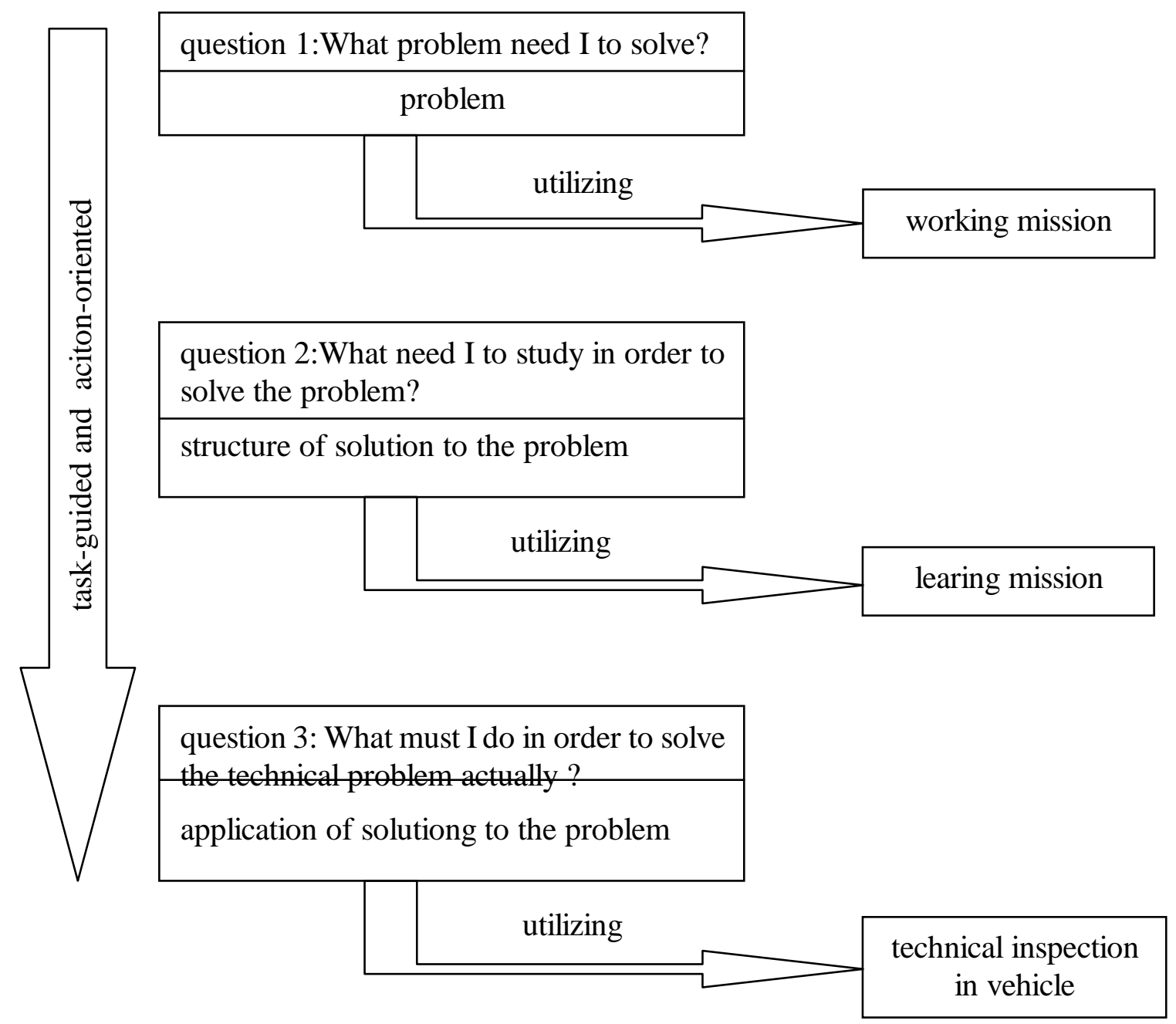

Figure 3. Plan and complete customer's commission independently

\section{Acknowledgements}

His work is supported by Shaanxi Higher Education Teaching Reform Research Project (No.15Z24), which sponsored by Education Department of Shaanxi Provincial Government.

\section{References}

[1] Hongliang LIN, Jianming GUO, Xuanmeng CUI, Dilemma and exploration to implement modern apprenticeship. Education and Vocation, Issue 11 of Volume 867, June 2016, p.29-32.

[2] Hongliang LIN, Jianming GUO, Xuanmeng CUI, On the Sino-Germany SGAVE Project Curriculum Model: From "Client Consignation" to "Qualification Matrix" .Vocational and Technical Education,No.8 of Vol.37,2016, p.74-77.

[3] Wenjin SHEN, Zhigang Zhou, From "Action Field" to "Learning Environment"----study on German "Learning Field" Curriculum Model. Comparative Education Review, No.6 of 2009, p.77-81.

[4] Dayuan JIANG. New Research about Vocational Education. (Education Science Press, China, 2007). 